УДК 32.019.51

МЕДУШЕВСКИЙ Николай Андреевич - доктор политических наук, профессор кафедры культуры мира и демократии Российского государственного гуманитарного университета (115446, Россия, г. Москва, Коломенский пр., 21; Lucky5659@yandex.ru)

\title{
КУЛЬТУРА СТРАХА СОВРЕМЕННОГО: В ДИАЛОГЕ С КНИГОЙ ЛЕШЕКА КОЧАНОВИЧА «ANXIETY AND LUCIDITY. REFLECTIONS ON CULTURE IN TIMES OF UNREST»
}

\begin{abstract}
Аннотация. Статья представляет собой рецензию на монографию Лешека Кочановича (Leszek Koczanowicz) "Anxiety and Lucidity. Reflections on Culture in Times of Unrest». Монография, название которой переводится как «Тревога и ясность сознания. Размышления о культуре во времена волнений», посвящена анализу феномена страха как социального явления, детерминирующего общественное поведение. В ней рассматриваются источники формирования социальной тревожности и факторы, влияющие на ее рост и распространение.
\end{abstract}

Ключевые слова: страх, общество, счастье, катастрофа, смерть, angor animi

$\mathrm{C}$ трах - это эмоциональное состояние человека, основанное на восприятии им реальной или воображаемой угрозы, способной привести к негативным последствиям ${ }^{1}$. Страх носит отрицательную эмоциональную окраску и связан с опытом, приобретенным личностью в процессе ее жизнедеятельности, хотя в отдельных случаях страх - это инстинктивная (инстинкт самосохранения) реакция на определенные внешние условия и раздражители [Захаров 2000].

Роль страха в жизнедеятельности человека неоднозначна. Так, в отдельных случаях он стимулирует мобилизацию организма, включая мыслительную деятельность и когнитивные способности. В иных случаях выраженный страх, наоборот, парализует волю индивида и блокирует любую когнитивную деятельность, оставляя только возможность инстинктивного поведения [Изард 2007].

В данной связи актуальным становится изучение страха одновременно как психического и как социального феномена. Актуальность в данном случае обусловлена тем, что человек, являясь социальным субъектом, существует в обществе, зависит от него и влияет на него. Как следствие, страх, рождаясь как индивидуальное эмоциональное состояние, может транслироваться индивидом на групповом уровне, формируя коллективные страхи и даже фобии, - здесь показательны примеры поведения толпы, описанные Лебоном [Лебон 2015].

Таким образом, страх постоянно существует в социуме, но в разные исторические периоды его объем варьируется в зависимости от существующих стрессогенов. Примеры исторических событий, ставших реакцией на общественный страх, присутствуют во многих работах, в т.ч. в исследовании «Анатомия страха. Трактат о храбрости» испанского автора Хосе Антонио Марина [Марина 2011].

Тем не менее феномен страха в современном обществе остается слабо изученной темой, и здесь особый интерес представляет работа 2020 г., принадлежащая перу польского автора Лешека Кочановича (Leszek Koczanowicz) «Anxiety and Lucidity. Reflections on Culture in Times of Unrest» [Koczanowicz 2020], название

\footnotetext{
1 Страх. - Толковый словарь живого великорусского языка: в 4 т. (авт.-сост. В.И. Даль). 2-е изд. СПб: Тип. М.О. Вольфа. 1880-1882. Доступ: https://dal.slovaronline.com/ (проверено 23.01.2021).
} 
которой можно перевести как «Тревога и ясность сознания. Размышления о культуре во времена волнений».

Данная работа имеет целью исследование современной культуры с точки зрения тревоги, которая проявляется в обществе в различных аспектах. Анализируя проблематику тревоги, Кочанович опирается на идеи Маркса, Ницше и Фрейда, что позволяет ему представить «культуру тревоги» как обратную сторону «культуры риска». Развитие обоих типов культуры является следствием нестабильности и волатильности современного мирового порядка, в котором присутствует запрос на изменение структуры от ее низовых элементов, таких как структура семьи, до макроэлементов, таких как структура государства или даже форма мирового порядка. Здесь особенно показательны разделы исследования, посвященные культуре беспокойства, феномену вины, влиянию исторической памяти на господствующие в обществе страхи, феномену призрачного, или воображаемого мира прошлого, влиянию прошлого (коммунистическая эпоха) на современную социальную обстановку и большую политику и т.д.

Работа Кочановича стала результатом его научной и исследовательской деятельности. Сам автор является профессором кафедры социальной психологии факультета психологии Института гуманитарных наук во Вроцлаве (Польша). Сфера его научных интересов - философия политики, концепции демократии и политической этики.

Книга «Anxiety and Lucidity. Reflections on Culture in Times of Unrest» является результатом осуществления научного проекта «Angor Animi» в рамках Института гуманитарных наук во Вроцлаве.

Данный проект, и это отражено в монографии, затрагивает ключевые проблемы современной культуры, связанные с тревогой и конфликтом, возникающим на различных уровнях. Речь идет о нестабильности общественных структур, кризисе личности, непредсказуемости завтрашнего дня, страхе внезапной смерти и жизни на грани смерти.

Все перечисленные проблемы объединяет единственный фактор - их восприятие человеком через страх, что восходит к работам Ульриха Бека и Люка Болтански, размышлявших над феноменом «жидкой современности», суть которой - нестабильность как социальных структур, так и личности.

Речь идет о постмодернистском взгляде на природу общества, и этот взгляд порождает культуру страха ввиду неопределенности. Страх существования провоцируется многими проблемами, в числе которых Кочанович называет тяжелую жизнь, разные грани смерти, чувство угрозы, давление и чувство вины. В данной связи показательно общее название исследования, которое присутствует и в монографии, - angor animi, означающее в медицинской интерпретации чувство приближающейся смерти. Данное чувство отличается и от «желания смерти», и от страха перед смертью. По своей сути оно нейтрально, но ставит человека перед условной пропастью, в которую он неминуемо должен упасть.

Рассматривая феномен страха, Кочанович экстраполирует его на разные формы социального бытия с целью его дальнейшего комплексного изучения. Так, например, он обращается к культуре повседневности и говорит о том, что ее конструкция предполагает некий парадокс, т.к., с одной стороны, она должна быть стабильной и обеспечивать точку отсчета бытия индивида, но, с другой - ее повторяемость бывает невыносимой, рутина становится источником тревожного чувства.

Второй феномен - это катастрофа. Здесь речь идет о том, что при всей стабильности общества оно не желает быть инертным и постоянно рискует в 
своем развитии. Особенно это усугубляется темпом его развития, который постоянно ускоряется. В итоге социум постоянно противопоставляет повышение уровня благополучия потенциальной катастрофе, которая приведет к его гибели (здесь показателен феномен «часов судного дня» в США). В данном противоборстве снова рождается страх общества, который в отдельных случаях способен сказаться на его прогрессивном развитии.

Третьим аспектом анализа Л. Кочановича становится смерть. Страх перед смертью естественен и сопровождает человека во все периоды его социального развития. Несмотря на это, автор трактует страх смерти иначе. Он говорит, что смерть в значительной степени приватизирована обществом и в социуме возникает много барьеров, которые позволяют человеку отгородиться от смерти и выдворить ее на периферию своего восприятия. Такими механизмами становятся страхование жизни, страхование автомобилей, медицинские исследования, хирургические операции, т.е. всевозможные механизмы, нацеленные на определение вероятности смерти. В то же время отдаление смерти от восприятия человека провоцирует увеличение страха перед ней как перед фактором неминуемого разрушения иллюзий безопасности и защищенности.

Кроме того, как ни парадоксально, развитию страха, в т.ч. страха смерти, в повседневной жизни способствует категория счастья. Исторически счастье понималось как некое исключительное состояние, которое человек может обрести только благодаря воле бога и в результате преодоления множества испытаний. Но с течением времени отношение к счастью менялось, и сегодня в развитых странах господствует идея, что каждый обладает правом на счастье, а само счастье становится универсальной категорией, связанной с повседневностью. В итоге отсутствие у кого-либо состояния счастья заставляет его рассматривать себя как дискриминируемого (по Кочановичу, «без вины виноватого») и, более того, испытывать страх из-за потенциальной угрозы не достигнуть счастья при жизни.

Дополнительным фактором, усугубляющим чувство страха у индивида и придающим страху универсальный социальный характер, становится разрушение единства нации и народа. Это в значительной степени обусловлено культурой материализма, которая, в свою очередь, способствует росту индивидуального самосознания отдельной личности. В итоге нация распадается на совокупность индивидов, испытывающих страх за свой статус, свое имущество и свою жизнь. Эти страхи получают широкое социальное выражение и начинают определять поведение общества, передаваясь от одного к другому и приобретая универсальные черты. В немалой степени этому способствует и сверхразвитая коммуникативная среда, не имеющая сегодня национальных и территориальных границ

Таким образом, вторя словам Л. Кочановича, можно констатировать, что современное общество заражено страхом, который разрушает его изнутри и ведет нации по пути неоправданных резких и часто деструктивных действий, обусловленных желанием мобилизоваться перед мнимыми вызовами, являющимися результатом воображаемых угроз.

Очевидно, что подход Лешека Кочановича к интерпретации реальности через страх представляет большой исследовательский интерес. Автор фактически создает новое измерение анализа социального, а во многом и политического поведения, что коррелирует с классическим восприятием общества как живого организма, обладающего в т.ч. и особой психологией.

Тем не менее представляется, что подход Кочановича вряд ли может претендовать на статус комплексного, т.к. страх является лишь одной из поведенческих характеристик, которая конкурирует с другими. Кроме того, и это демон- 
стрирует опыт изучения фобий в психологии, страх является ответом психики индивида на конкретный проблемный внешний вызов, т.е. общество, как и человек, не склонно бояться всего и вся, что, в свою очередь, открывает путь к новым, более комплексным проектам по изучению общественного поведения.

\section{Список литературы}

Захаров А.И. 2000. Дневные и ночные страхи у детей. СПб: Союз. 448 с.

Изард К.Э. 2007. Страх и тревога. - Психология эмоций. СПб: Питер. 464 с.

Лебон Г. 2015. Психология народов и масс (пер. с фр. А. Фридмана, Э. Пименовой). 3-е изд. М.: Академический проект. 239 с.

Марина Х.А. 2011. Анатомия страха. Трактат о храбрости. М.: Астрель. 382 с.

Koczanowicz L. 2020. Anxiety and Lucidity. Reflections on Culture in Times of Unrest. Oxford: Routledge. 198 p.

\section{THE CULTURE OF FEAR OF THE MODERN: IN DIALOGUE WITH LESZEK KOCHANOVICH'S BOOK «ANXIETY AND LUCIDITY. REFLECTIONS ON CULTURE IN TIMES OF UNREST»}

\footnotetext{
Abstract. The article is a review of the monograph by Leszek Koczanowicz "Anxiety and Lucidity. Reflections on Culture in Times of Unrest» published in 2020. The monograph is devoted to the analysis of the fear phenomenon as a social appearance that determines social behavior. The book examines the sources of social anxiety formation and the factors influencing its growth and spread.

Keywords: fear, society, happiness, catastrophe, death, angor animi
} 